\title{
Opinion on a Reliable Rock Engineering Tool- Box for Mining Industry
}

ISSN: 2578-0255

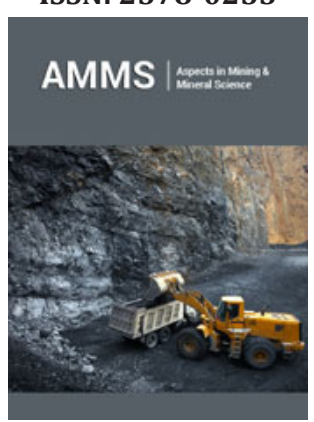

*Corresponding author: Nghia Trinh and Eivind Grøv, SINTEF Community Department of Infrastructure, Norway

Submission: 望 April 21, 2020

Published: 㱕 May 14, 2020

Volume 4 - Issue 5

How to cite this article: Nghia Trinh Eivind Grøv. Opinion on a Reliable Rock Engineering Tool-Box for Mining Industry. Aspects Min Miner Sci. 4(5). AMMS.000599. 2020.

DOI: 10.31031/AMMS.2020.04.000599

Copyright@ Eivind Grøv, This article is distributed under the terms of the Creative Commons Attribution 4.0 International License, which permits unrestricted use and redistribution provided that the original author and source are credited.

\author{
Nghia Trinh and Eivind Grøv* \\ SINTEF Community Department of Infrastructure, Norway
}

Opinion

Along the development of human being, there are several important inventions that completely change the way we live. Such inventions may be "fire", "electricity", and now "Information Technology - IT". It is difficult to imagine our life now without IT, and it is the same situation in mining industry. It is quite common today that rock engineering projects in general, and particularly mining projects are planned and developed with help of computer added tool-numerical model. The model can be performed in 2D or 3D in order to provide engineering parameters for decision making. The engineering parameters can be development and distribution of stress, strain, and displacement for stability analyses. It can also be vibration and seismicity related to mining process, and so on.... Information provided from numerical models is always an important source of information making decision. However, decision makers are always "stuck" with a question that "How can I trust the information from numerical model?" In our opinion, it is a long process with a more complete toolbox rather than only numerical model alone for appropriately to answer to that question. With over 50 years of research and development, SINTEF has developed a reliable rock engineering tool to deal with the challenges. The tool is a combination of three components "investigation tools", "numerical modelling", and "site monitoring". We use the term "TRIPOD" for the methodology.

\section{Stress measurements by SINTEF}

Since the late 1960 ies we have developed equipment for in-situ rock stress measurements. This also includes equipment for long-term monitoring of rock stresses. The present applied techniques are:

A. Self-developed and highly improved versions of the originally South African CSIR

2-D Doorstopper

B. 3-D CSIR over coring cells.

C. Self-developed hydraulic fracturing equipment

These methods have been continuously improved through extensive research and application over the last 50 years. The described techniques have been used widely in various projects, including mining industry, hydropower, oil and gas storage, and infrastructures in many countries around the world. Our reference list comprises 150 locations in18 countries. As each client or location may represent a number of measuring sites, the total number of sites/measuring holes are in the order of 330, corresponding to approximately 3000 single measurements.

\section{Stress monitoring by SINTEF}

SINTEF/NTNU has developed a special version of the "door-stopper" for long term monitoring purposes which appear to behave stable. During drilling of the hole, standard doorstopper measurements are taken at selected intervals to obtain the initial stresses. The last measurement is taken as close as possible to the selected depth of the monitoring doorstopper, and this value is taken as initial value for the monitoring equipment After installation of the door-stopper, strain change in the rock can be recorded, and the correspondent stress 
change can be estimated. Depending on the configuration, the data can be logged at any time interval and transferred real time to a server for processing. Figure 1 shows the long term door-stopper before and after installation.

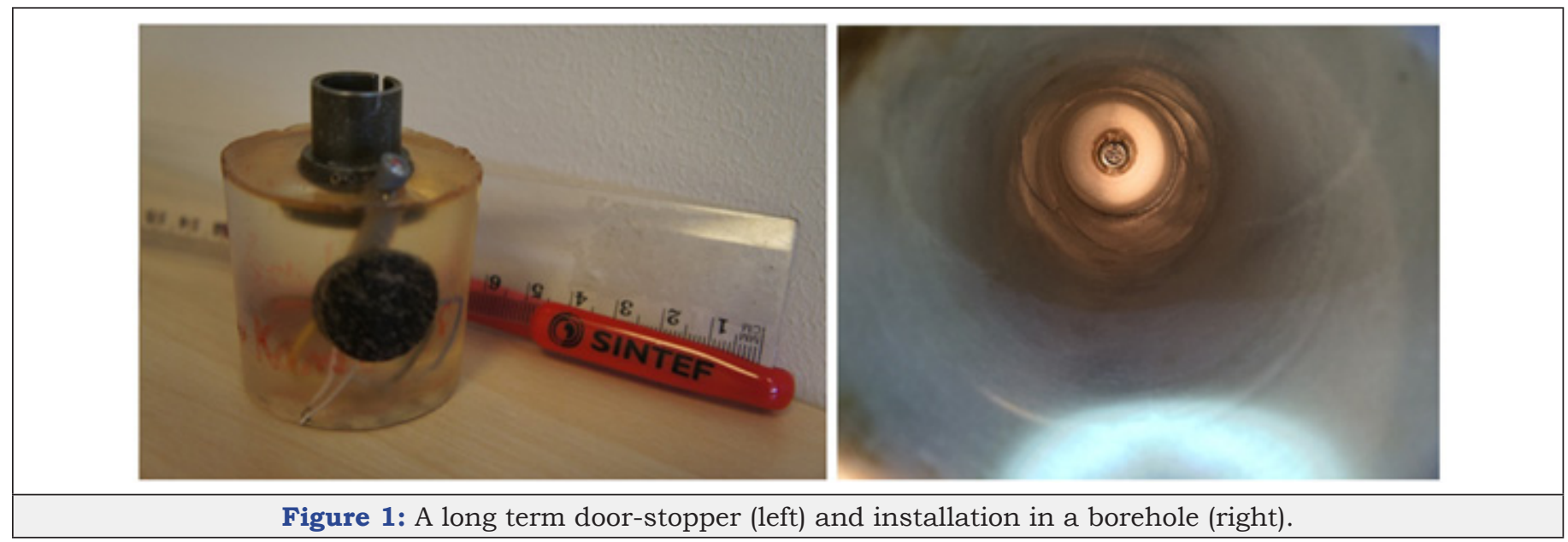

TRIPOD: Combination of stress measurement-numerical modelling-site monitoring

Over the time, SINTEF develops a toolbox to deal with rock engineering challenges at different levels. The tool is a combination of three components "Investigation tools-Numerical modelling-Monitoring". Our investigation tools are including stress measurement, laboratory tests, and geological mapping. Stress measurements were carried out before and during construction phase of the project. The measurements included both 2-D and 3-D in relevant locations close to the concerned area. Laboratory tests for obtaining intact rock mechanics properties were carried out in connection with the stress measurements. Geological mapping was carried out to obtain the rock mass characteristics and conditions of the site [1]. The investigations provide inputs for the numerical model. Based on these inputs, a reliable numerical model can be established to provide information for further evaluation and decision-making. To increase the reliability of the model even further, it is then followed, verified, and improved along the way by communicating with monitoring equipment. Any discrepancy between the model and in-situ observation or monitoring data must be studied carefully in order to detect the pitfalls and possible improvement. A recommended working model for combining stress measurement, laboratory, numerical modelling, and monitoring is shown in Figure 2.

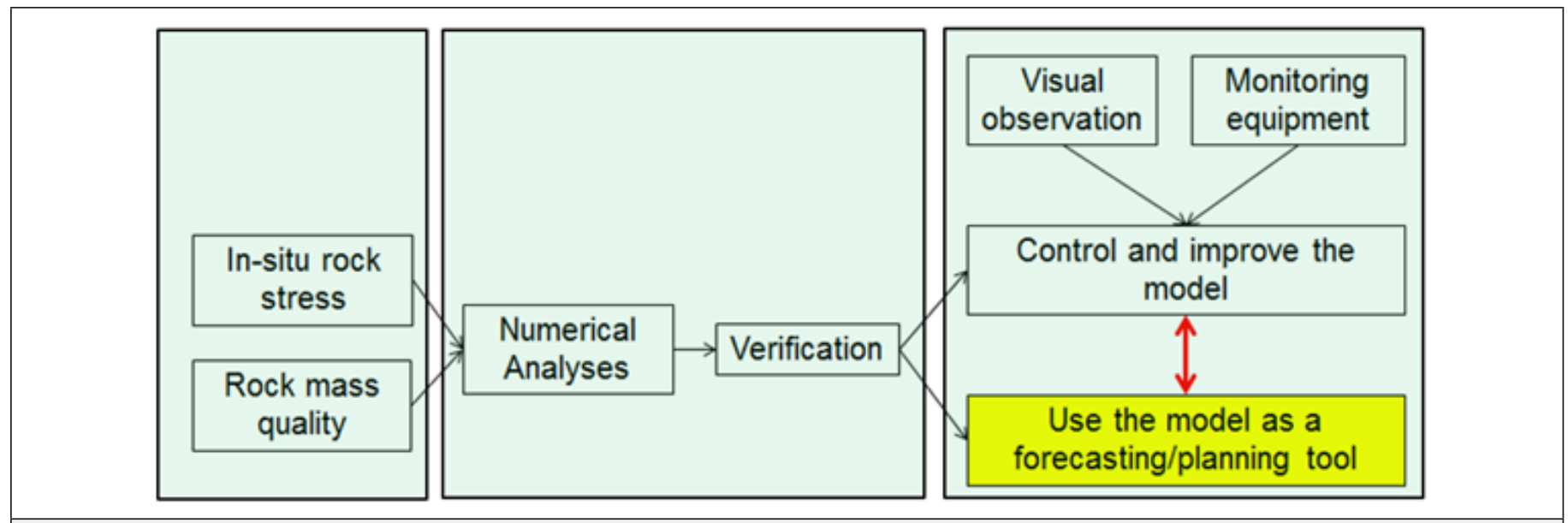

Figure 2: Recommended working model for combining measurement, laboratory, numerical modelling, and monitoring [2].

\section{TRIPOD for development of the iron ore production at rana gruber, Norway}

The Rana Gruber is an iron mine in the North of Norway, $30 \mathrm{~km}$ east of Mo i Rana. The mine is located in a foliated gneiss host rock, and the ore body is about $70 \mathrm{~m}$ wide and more than $300 \mathrm{~m}$ deep. Different mining methods have been used, including open pit mining and sublevel stopping. Since 2009, the production has changed gradually to sublevel caving creating considerations in rock mechanic aspects. The TRIPOD was extensively used in this mine for almost last 10 years. The toolbox was considered as an important tool to assist the planning team during both planning and implementation of the mining method change at the mine. More than 18 stress measurements have been done over the years since 1977. Sixteen long-term-door-stoppers (LTDM) were installed at 
critical locations to monitor the stress development in the rock mass during mining progress. The development and component of the LTDM was presented in Trinh et al. [2]. Two extensometers were installed to monitor the displacement at the footwall of the mine. Comprehensive 2D and 3D numerical models (Figure 3) were established to study the existing condition and to test different mining alternatives. With a meticulous follow-up program, the data from the monitoring equipment was used for model calibration and verification. The model was improved and become a reliable tool for planning and operation of the mine.

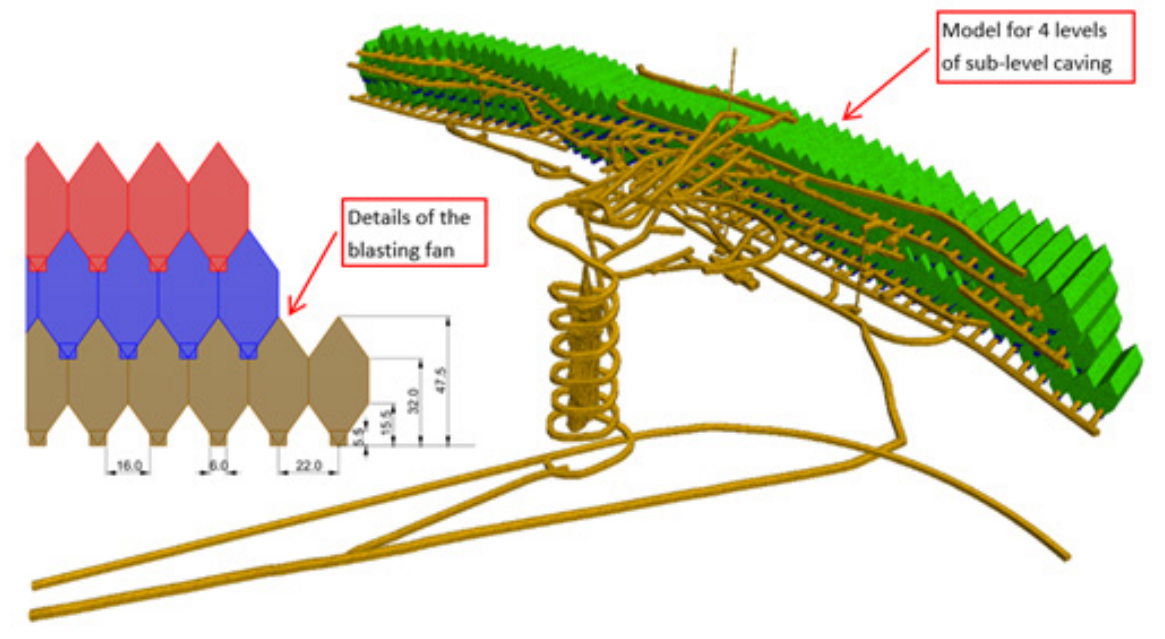

Figure 3: 3D numerical model for Rana Gruber.

\section{References}

1. Hanne Wiig, Marcus Lawton (2018) Drill \& Split Follobanen D\&B. Applied Rock Mechanics, Norway.
2. Trinh QN, Holmøy HK, Larsen T, Myrvang A (2016) Continued rock stress and displacement measurements combined with numerical modeling as an active, realistic rock engineering tool. RS2016 Symposium, $7^{\text {th }}$ International Symposium on In-Situ Rock Stress, Finland. 